\title{
As relações com os saberes no processo de orientação acadêmica de professoras- pesquisadoras de educação física escolar
}

\section{Relationships to knowledge in the academic advising process of school physical education teachers-researchers}

https://doi.org/10.34112/2317-0972a2021V39n82p73-90

LUCIANA VENÂNCIO ${ }^{1}$

Cyntia Emanuelle Souza Lima ${ }^{2}$

Emmanuelle Cynthia da Silva Ferreira ${ }^{3}$

RESUMO: O processo de orientação no campo acadêmico é permeado por relações de poder, hierárquicas e institucionalizadas, que valorizam os saberes de orientadores(as) em detrimento dos saberes de orientandos(as). Há também interseccionalidades nessas relações, como questões étnico-raciais, de gênero e classe social. Reconhecer essa complexidade relacional implica na reflexão sobre pautas específicas da justiça social - como o antirracismo, o antissexismo e o anticapitalismo - na formação de professores(as)-pesquisadores(as). Neste artigo, três coautoras - uma orientadora e duas orientandas - que investigam a noção de relação com o saber analisam as suas próprias relações com os saberes em um processo de orientação acadêmica. O objetivo é situar as reflexões sobre as escolhas metodológicas baseadas nas narrativas de saberes das três professoras-pesquisadoras. A temática abrange aproximações teórico-metodológicas - no âmbito da orientação acadêmica em um programa de pós-graduação em educação física - e narrativas que se entrelaçam na mobilização para aprender em um grupo de pesquisa.

Palavras-chave: Relação com o saber; escola pública; Bernard Charlot.

1. Universidade Federal do Ceará, Fortaleza, PE, Brasil; Universidade Federal do Rio Grande do Norte, Natal, RN, Brasil.

2. Universidade Federal do Rio Grande do Norte, Natal, RN, Brasil.

3. Universidade Federal do Rio Grande do Norte, Natal, RN, Brasil. 
As relações com os saberes no processo de orientação acadêmica de...

ABSTRACT: The advising process in the academic field is permeated by power-based relationships - hierarchical and institutionalized - regarding the valorization of the knowledge of advisors in detriment of the students' knowledge. There are also intersectionalities in these relationships, such as ethnic-racial, gender and social class issues. Recognizing this relational complexity implies reflecting on specific social justice guidelines - such as anti-racism, anti-sexism and anti-capitalism - in teacher-researchers education. In this article, three co-authors - one advisor and two advisees - who investigate the relationship to knowledge theory analyze their own relationships to knowledge in an academic advising process. The objective is to situate the reflections on the methodological choices based on the three teacher-researchers' narratives of knowledge. The theme covers theoretical-methodological approaches - within the scope of academic advising in a physical education postgraduate program - and narratives that are intertwined in the mobilization to learn within a research group.

KEYWORDS: Relationship to knowledge; public school; Bernard Charlot.

\section{INTRODUÇÃO}

Há processos complexos envolvidos na elaboração de saberes durante a formação inicial e continuada de professores(as), que repercutem também nos programas de pós-graduação e nas diversas comunidades científicas. Assim como muitos(as) agentes envolvidos(as) na complexidade desses processos formativos, temo-nos esforçado para identificar e compreender os efeitos da pandemia do novo coronavírus SARS-CoV-2 (Covid-19) nos mais variados contextos educacionais - sobretudo nas escolas públicas -, caracterizados por desigualdades nas diferentes regiões brasileiras (SILVA et al., 2021). Decorrido quase um ano desde a confirmação do primeiro caso de Covid-19 no Brasil ${ }^{4}$, entendemos que é importante compartilhar como essa situação de impacto mundial tem influenciado a reorganização do pensamento pedagógico e das reflexões de quem está envolvido(a) com a elaboração de pesquisas com o foco na educação básica. Nesse período, as aulas foram suspensas na educação básica e no ensino superior - afetando os programas de pós-graduação das universidades públicas brasileiras -, até obtermos informações minimamente adequadas, que pudessem colaborar com a tomada de decisão sobre planos emergenciais para retomarmos as atividades de ensino, pesquisa e extensão de forma remota.

4. O primeiro caso de Covid-19 no Brasil foi reportado em fevereiro de 2020, e as primeiras ações sistemáticas de lockdown (isolamento social obrigatório) ocorreram em meados de março, com implicações diferentes em cada estado e município. 
Mais importante, vimos o impacto causado nas vidas perdidas e a explicitação, cada vez mais aguda, das desigualdades sociais já há muito tempo denunciadas. Muitas injustiças sociais continuam a ocorrer, e o descaso do governo brasileiro caracteriza a barbárie (CHARLOT, 2019, 2020). Apesar da disponibilidade das tecnologias da informação e da comunicação (TIC), temos visto um abismo acentuadíssimo entre quem tem acesso e sabe utilizá-las, quem tem poucos recursos (conhecimentos específicos e/ou dinheiro disponível para garantir o acesso) para usá-las mesmo e quem não tem acesso nem recursos. Essas condições também implicaram na condição de vida de professores(as)-pesquisadores(as) - quem se dedica à pesquisa vinculada à docência (ELLIOTT, 2017) - nos programas de pós-graduação. Os cronogramas das pesquisas e os modos de realizar as orientações acadêmicas e os encontros dos grupos de estudos foram repensados, passando a ser virtuais. A principal preocupação tem sido com a condição humana (ARENDT, 2007) - que compreende a saúde orgânica, a sanidade mental e o bem viver - de cada um(a) e dos(as) familiares.

Paulatinamente, as questões que implicavam as pesquisas em andamento começaram a ser repensadas, à medida que as atividades remotas nas escolas e nas universidades ocorriam. Nesse sentido, uma série de reflexões emergiram a respeito da função social das ciências e da pertinência do que estamos fazendo para o bem viver comum. Para minimizar o impacto do isolamento social, buscamos maneiras de fortalecer a acolhida no grupo de estudos e no processo de orientação. Um desafio foi refletir coletivamente sobre o sentido de continuar estudando a teoria da relação com o saber para ancorar teórica e metodologicamente as pesquisas em educação física escolar. Questionamo-nos: Até que ponto os projetos iniciados antes da pandemia continuavam a fazer sentido?

Para chegar a uma resposta, refletimos sobre nossa própria trajetória. Desde 2017, quando iniciamos o estudo mais aprofundado e a pesquisa de modo sistemático em um grupo na área de educação física escolar, comprometemo-nos a responder, ainda que provisoriamente, a questão feita por Charlot (2000a, p. 79): "Que faz o(a) pesquisador(a) que estuda a relação com o saber?”. Procuramos apresentar - em Nobre et al. (2019), Venâncio (2019), Venâncio e Sanches Neto (2018) - algumas possibilidades que encontramos para confrontar os desafios de consolidar a educação física escolar como um componente curricular que possui saberes a serem apropriados, já que é um componente curricular preexistente e precisa que os(as) alunos(as), juntamente com os(as) seus(suas) professores(as), qualifiquem as suas vivências e experiências à medida que se reconhecem como sujeitos de saberes. 
As relações com os saberes no processo de orientação acadêmica de...

Neste artigo, nós três - uma orientadora (Luciana) e duas orientandas (Cyntia e Emmanuelle) que investigam a noção de relação com o saber - analisamos as nossas próprias relações com os saberes em um processo de orientação no mestrado acadêmico. Nosso objetivo é situar as reflexões - relatadas em narrativas de saberes, elaboradas pelas três professoras-pesquisadoras - a respeito das escolhas metodológicas sobre o porquê de estudar e pesquisar a teoria da relação com o saber a partir do contexto da educação física escolar. A temática abrange a complexidade das aproximações teórico-metodológicas - no âmbito da orientação acadêmica no Programa de Pós-Graduação em Educação Física da Universidade Federal do Rio Grande do Norte (PPGEF-UFRN) - às narrativas, que se entrelaçam na mobilização para aprender, no âmbito do Grupo de Estudos e Pesquisas em Educação Física Escolar e Relações com os Saberes (GEPEFERSs) da Universidade Federal do Ceará (UFC). Os indícios que encontramos apontam para uma ampliação dos entendimentos da educação física escolar como área de intervenção pedagógica, ancorada na teoria da relação com o saber de modo crítico, colaborativo e emancipatório.

Entendemos que o processo de orientação no campo acadêmico é permeado por relações de poder - hierárquicas e institucionalizadas - que valorizam os saberes de orientadores(as), em detrimento dos saberes de orientandos(as). Contudo, há também interseccionalidades nessas relações, como questões étnico-raciais, de gênero e de classe social. Para nós - como trabalhadoras da educação na América Latina, como mulheres negras e professoras-pesquisadoras de educação física essa perspectiva não pode ser invisibilizada (SANCHES NETO; VENÂNCIO, 2020; VENÂNCIO; NOBREGA, 2020). O reconhecimento dessa complexidade relacional implica na reflexão sobre pautas específicas da justiça social - como o antirracismo, o antissexismo e o anticapitalismo - na formação de professores(as)-pesquisadores(as). De acordo com Collins (2017), é importante compreender como as vozes das mulheres negras coletivamente constroem, afirmam e mantêm um ponto de vista autodefinido e dinâmico. Nesse âmbito, Silva e Bernardes (2007) advertem que precisamos reconhecer que a educação ultrapassa a instrução formal porque tem a ver com o domínio de si próprio(a), e os currículos precisam ser flexíveis para integrar todos os povos. Por isso temos muito o que fazer como professoras-pesquisadoras preocupadas com as relações com os saberes e a justiça social.

5. O GEPEFERS foi criado em 2017 no Instituto de Educação Física e Esportes da UFC, faz parte da Rede de Pesquisa sobre Relação com o Saber (Rede Repères) e está cadastrado no diretório de grupos do CNPq. Disponível em: dgp.cnpq.br/dgp/espelhogrupo/o801245964431748. Acesso em: 7 fev. 2021. 


\section{ESCOLHAS METODOLÓGICAS}

Esta é uma pesquisa qualitativa com enfoque narrativo. A pesquisa qualitativa sinaliza para os(as) pesquisadores(as) desafios que poderão ser superados com novas perguntas, que significam novos modos de pesquisar e, consequentemente, novos enfoques paradigmáticos emergem (SANDÍN-ESTEBAN, 2010). Temo-nos dedicado à investigação da teoria da relação com o saber (CHARLOT, 2000a) individualmente, em nossos projetos de pesquisa, e juntas no GEPEFERS (VENÂNCIO, 2014, 2019). Contudo, o nosso principal desafio metodológico é escolher um caminho reflexivo que permita uma relação horizontalizada entre nós, a despeito da relação de poder institucionalizada no PPGEF-UFRN às três professoras-pesquisadoras. Em nossos esforços, temos estudado de modo colaborativo vários aspectos da teoria, na perspectiva de criticar - com leituras positivas e negativas - e difundir os achados no campo de investigação da educação física escolar, subsidiada pelas ciências humanas e com foco nas escolas públicas da região de Fortaleza. A nossa primeira escolha, portanto, é por um percurso qualitativo que respeita os itinerários (auto)formativos das professoras-pesquisadoras (LUTTRELL, 2010). Em relação às condições preexistentes em nossas trajetórias, entendemos que a relação orientadora-orientandas se dá a posteriori.

De acordo com Charlot (2000a), os saberes materializam-se nos corpos dos próprios sujeitos quando demonstram interesses, identificam-se com o que se apresenta e estabelecem relações identitárias. A relação identitária com o saber deduz que aprender faz sentido por referência às histórias dos sujeitos, às expectativas, às suas referências, às suas concepções de vida, às imagens que têm de si mesmos(as) e às que querem dar de si aos(às) outros(as). Já a relação social com o saber demanda tempo de inscrição, de se lançar ao mundo com os(as) outros(as), numa rede de relações de posições sociais preexistentes. Esse desafio metodológico identitário e social diz respeito, especificamente, ao processo de orientação subjacente à relação entre as três professoras-pesquisadoras. Para explicitar as perspectivas (inter) subjetivas, a nossa opção recaiu na escrita narrativa de si. Assim, as nossas escolhas metodológicas para gerar indícios das relações com os saberes que estabelecemos com a própria história de vida foram explicitadas em formato de narrativas (de experiências) de saberes (VENÂNCIO; SANCHES NETO, 2019).

A ênfase nas narrativas tem favorecido a ampliação de discussões a respeito de temáticas complexas e o aprofundamento de possibilidades interdisciplinares de saberes no campo educativo (GOMES, 2017; JOSSO, 2020; VENÂNCIO; 
NOBREGA, 2020). Nessa lógica, a educação física tem incorporado perspectivas que valorizam a (inter)subjetividade das vivências, bem como os modos e as razões autorais nas narrativas das experiências de vida e de formação (VENÂNCIO; SANCHES NETO, 2019). Por um lado, as narrativas permitem identificar e compreender como as disposições e as escolhas de cada sujeito se entrelaçam diante da sua posição de origem no mundo, ou melhor, da sua relação com o mundo. Por outro lado, permitem situar criticamente o que emerge como mais significativo na experiência de cada sujeito. Como dispositivo metodológico qualitativo, as narrativas constituem também processos de exposição das experiências de sujeitos que se propõem ao risco de narrar.

O sujeito da experiência é um sujeito ex-posto. Do ponto de vista da experiência, o importante não é nem a posição (nossa maneira de pormos), nem a oposição (nossa maneira de opormos), nem a imposição (nossa maneira de impormos), nem a proposição (nossa maneira de propormos), mas a ex-posição, nossa maneira de ex-pormos, com tudo o que isso tem de vulnerabilidade e risco. Por isso é incapaz de experiência aquele que se põe, ou se opõe, ou se impõe, ou se propõe, mas não se ex-põe. É incapaz de experiência aquele a quem nada lhe passa, a quem nada lhe acontece, a quem nada lhe sucede, a quem nada o toca, nada lhe chega, nada o afeta, a quem nada o ameaça, a quem nada ocorre. (LARROSA BONDÍA, 2014, p. 26).

Elaboramos sínteses das nossas narrativas de saberes, nas quais assumimos uma posição autoral como professoras-pesquisadoras. Solicitamos que cada uma, a seu modo de narrar, explicitasse as referências predominantes para ampliar a própria compreensão da relação com o saber, bem como confrontá-la com outros aportes teóricos. Apresentaremos a seguir excertos das três sínteses narrativas e as analisaremos posteriormente, à luz das dimensões identitária, social e epistêmica com o saber (CHARLOT, 2000a). No processo compartilhado de análise, buscamos situar as nossas reflexões sobre as escolhas - porque cada escolha tem caráter autoral - e consideramos como os excertos se coadunam às dimensões propostas por Charlot (2000a). Na medida em que escolhemos um caminho intersubjetivo e reflexivo para a pesquisa, assumimos um percurso metodológico de forma coautoral. 


\section{A RelaÇÃo Da PROFESSORA-PESQUisadora CyNtia COM O SABER}

Ao receber o convite da professora orientadora para escrever uma narrativa e refletir junto com ela sobre o sentido da própria relação com os saberes, Cyntia sentiu-se extremamente desafiada. Apesar de estar no GEPEFERS há algum tempo, ela estava em um estágio diferente do atual. Ao reler tempos depois a sua narrativa, identificou duas lacunas: (i) a dificuldade em escrever a narrativa de forma pessoal a orientadora havia alertado sobre o uso desnecessário de referências para justificar algumas posições - e (ii) a percepção sobre as alterações no próprio entendimento a respeito da relação com o saber, conforme as ideias vão amadurecendo mediante novas leituras e discussões. Além disso, Cyntia reconhece que a conclusão do curso de licenciatura em educação física - no período preestabelecido pela UFC como ideal para integralização curricular - foi repleta de tensões. Concomitantemente à elaboração do trabalho de conclusão de curso, Cyntia estava vivenciando o processo seletivo do mestrado no PPGEF-UFRN. Embora a participação no GEPEFERS fosse importante à sua formação, Cyntia se sentia deslocada porque poderia contribuir mais. Por isso, no processo de reescrita da narrativa, Cyntia percebeu que se encontra em um outro lócus epistemológico espaço-temporal, porque as suas percepções da relação com o saber já não são as mesmas. No mês passado ${ }^{6}$ completou um ano desde a conclusão da formação inicial como professora de educação física.

Cyntia prefere não utilizar o termo "formada" relativamente à conclusão da licenciatura e ao ingresso no mestrado, porque reconhece que todos(as) estamos em constante processo de (auto)formação (ABREU; NÓBREGA-THERRIEN, 2021). A partir dessa percepção, ela aceitou o desafio de revisitar as nossas relações com os saberes. A relação de Cyntia com a educação física perpassou meandros complexos e, para ela, as instituições de ensino são um mecanismo de manutenção do poder (APPLE, 2006). Por exemplo, durante a licenciatura ela escolheu escrever sobre a importância da educação física no ensino médio e se envolveu na mobilização de estudantes contra a "PEC da morte", ocupando o bloco didático do Instituto de Educação Física e Esportes. Cyntia percebeu que a relação com o saber de cada sujeito está associada à

6. A professora-pesquisadora Cyntia colou grau no curso de licenciatura em educação física em 14 janeiro de 2020.

7. Trata-se da proposta de emenda constitucional (PEC) n. ${ }^{\circ} 241$, aprovada como emenda n. ${ }^{\circ}$ 95, em 13 dez. 2016. A emenda evidenciou a fragilização das conquistas democráticas da Constituição Federal de 1988, assim como das políticas públicas educacionais por meio da medida provisória (MP) n. ${ }^{\circ} 746$, de 22 set. 2016, que instituiu a reforma do ensino médio. 
As relações com os saberes no processo de orientação acadêmica de...

configuração das desigualdades sociais, como o sexismo (CHARLOT, 2005). A escola, como reflexo da sociedade, não está isenta da política, e o currículo não é neutro (CHARLOT, 2013b). É necessário considerar a individualidade, a posição social, o sentido e as práticas dos(as) alunos(as) para compreender sua relação com o saber, sobretudo no contexto pandêmico, que agrava inseguranças, medos e traumas.

A ideia falaciosa de fracasso escolar também ocupou as reflexões de Cyntia, que associou o seu entendimento inicial ao convívio familiar. Cyntia compreendeu que sua mãe antecipara estereótipos que seriam atribuídos a ela, reforçando a necessidade de esforçar-se nos estudos. Por isso, quando lê alguma pensadora feminista, tenta relacionar as ideias à teoria da relação com o saber. E identificou que o feminismo se preocupa em motivar o engajamento, mas não com o sentido de mobilizar os sujeitos (CHARLOT, 2013a). Cyntia luta por pautas de determinadas mulheres e considera que o seu feminismo é excludente e segregacionista ${ }^{8}$ (hooks, 2017). Para ela, enquanto há vida, há relação e aprendizagens, por isso as relações com os saberes estão sempre presentes. Cyntia percebeu que é uma leitora mais sagaz após seu ingresso no mestrado e, como (auto)crítica, aponta que vê com outro olhar sua desilusão com o sistema educacional. Não obstante, prevê que daqui a alguns anos provavelmente esse olhar também sofrerá alterações. Ao relacionar as figuras do aprender - saber-objeto, saber-domínio e saber-relacional (CHARLOT, 200oa) - com a estratégia do planejamento participativo, Cyntia compreendeu que lutar pela educação democrática é uma tarefa complexa, mas possível (FLOR et al., 2020; LIMA et al., 2020).

\section{A RELAÇÃo DA PROFESSORA-PESQUISADORA EMMANUELLE COM O SABER}

Emmanuelle colocou-se em uma posição reflexiva, com o convite para repensar as relações com os saberes. Quando cursava a licenciatura, compartilhou com Luciana a concepção do GEPEFERS, que no início era um eixo temático de outro grupo. A cada vez que relê sua narrativa, Emmanuelle sente que ainda há algo a debater com Cyntia ${ }^{9}$ Luciana, porque há chance de encontrarmos mais desdobramentos. Por isso, retomar

8. Cyntia cita a música "É tudo para ontem", de Emicida, para indicar que tudo o que temos na vida somos nós mesmos(as). Disponível em: https://www.youtube.com/user/emicida. Ela menciona também o verso "Ano passado eu morri, mas esse ano eu não morro", da música "Sujeito de sorte", de Belchior, para indicar o sentido de sua revolta. Disponível em: https://www.youtube.com/watch?v=oysw9mWrzBg. Acesso em: 7 fev. 2021.

9. As duas professoras-pesquisadoras têm os mesmos nomes em posições de registro diferentes: Emmanuelle Cynthia e Cyntia Emanuelle, carinhosamente apelidadas de vice-versa. Ambas aprenderam a respeitar sua individualidade e estabelecer uma relação de reciprocidade diante da condição humana atual. 
o próprio percurso investigativo sobre a relação com o saber é um desafio paradoxal porque é constantemente novo - para revelar como entendemos nossa própria relação com o saber. Assim, o processo contínuo de aprendizagens ao longo da vida implica compreender que as relações com os saberes são dinâmicas e não inertes, pois estamos fadados(as) a aprender (CHARLOT, 2000a). Como assevera hooks (2019, p. 200), “o aprendizado precisa ser aprendido como uma experiência que enriquece a vida em sua integridade". Contudo, alguns seres humanos parecem confluir para um processo de aprendizagem restritivo ou desacreditar os próprios aprendizados. $\mathrm{Ou}$, ainda, suas relações com os saberes são contrárias ao bem viver da humanidade.

Emmanuelle completará em breve um ano de lotação como professora em escola pública da rede municipal de Fortaleza e considera-se inexperiente na docência. Entretanto, ela tem a esperança de uma educação democrática e busca a justiça social em suas práticas pedagógicas. Sua narrativa revela que a temática política é integrante da dimensão identitária de sua relação com o saber. Hoje, ela identifica ainda mais temáticas necessárias e faz uma autocrítica do que anteriormente imaginava para si quando trabalhasse como professora. Por exemplo, Emmanuelle se recorda de uma professora na licenciatura que citou a vida política e outros argumentos cabíveis às experiências dos(as) demais estudantes da turma. Imediatamente, Emmanuelle refletiu sobre o Centro Acadêmico dos(as) estudantes, do qual fazia parte, e constatou que não havia qualquer expectativa futura sobre eventuais implicações da sua intervenção naquele espaço. Era necessário transitar da posição de estudante para a de professora. Ela entendeu que a educação tem um significado político de classe que repercute na docência (CHARLOT, 2013b).

Para Emmanuelle, não há separação entre aquilo que nos permeia em um modelo macroscópico de sociedade e o cotidiano escolar, que seria microscópico. Cada vez mais, Emmanuelle compreende a necessidade de participar criticamente dos processos políticos da vida em sociedade, pois a educação é diretamente afetada. Ela vivenciou um longo período de formação inicial em duas instituições federais: o Instituto Federal de Educação, Ciência e Tecnologia do Ceará (IFCE) ${ }^{10}$ e a UFC. O desejo de descobrir a própria relação com o saber havia mobilizado Emmanuelle para os encontros do grupo de estudos e pesquisa, como uma oportunidade para identificar sentidos

10. Quando Emmanuelle decidiu ser professora, havia iniciado o curso de licenciatura em Educação Física no campus Canindé do IFCE. Posteriormente, transferiu-se para a UFC, porém somente havia vaga para o curso de bacharelado, o que levou à sua permanência na graduação por mais tempo, até conseguir uma nova vaga e concluir a licenciatura. 
e conexões no percurso (auto)formativo. E o desejo de aprender a fez permanecer. Então, Emmanuelle concorda com Charlot (2005) que cada sujeito precisa estudar a sua relação com o saber, pois faz parte de estar no mundo. Assumindo-se como uma professora progressista, ela explica que a configuração antropológica e social da relação com o saber compreende as desigualdades sociais que constituem o sujeito e, por isso, precisamos refletir criticamente sobre as relações de poder (CHARLOT, 2005). Nesse sentido, ela se faz duas questões: Que alunos(as) são esses(as) para quem ensinamos educação física? Que professora sou eu, quais as minhas relações de saberes e as dos(as) meus(as) alunos(as)? A partir dessas questões, Emmanuelle reflete sobre os ataques negacionistas à educação e à ciência, sobre a complexidade da relação entre a política e a educação, sobre sua própria identidade profissional como professora e sobre os elos viáveis entre a universidade e a escola (CHARLOT, 2006).

\section{A RELAÇÃo DA PROFESSORA-PESQUISADORA LUCIANA COM O SABER}

O contexto pandêmico de isolamento social para preservar as vidas humanas provocou reflexões em Luciana, como repensar o propósito do GEPEFERS e o processo de orientação acadêmica, que detém uma relação hierárquica. Para Luciana, o processo de construção metodológica tem gerado mobilizações que reverberam a curiosidade (auto)crítica, sensível e intuitiva. A coordenação do GEPEFERS lhe permite pesquisar, com ações coletivas, a teoria da relação com o saber, enquanto amplia as fronteiras epistemológicas na educação física escolar. $O$ interesse inicial de Luciana pela relação com o saber (CHARLOT, 1979, 2000a, 2013b) ocorreu no mestrado e foi ressignificado no doutorado, ao investigar o próprio modo de ensinar educação física (VENÂNCIO, 2005, 2014). Ela pesquisou as relações com os saberes de um grupo de ex-alunos(as) em uma escola municipal na periferia da zona leste de São Paulo e utilizou estratégias narrativas, grupos focais e entrevistas de explicitação para que os(as) estudantes desvelassem suas próprias vivências, experiências, pensamentos e argumentos com a educação física. Posteriormente, aprofundou ainda mais o escopo da pesquisa no pós-doutorado, ao investigar a temporalidade nas relações com os saberes de duas ex-alunas, ambas mulheres negras (VENÂNCIO, 2019).

Luciana acredita que novas ressignificações podem emergir e novos pontos de vista precisem ser explicitados. Como uma teoria socioantropológica de enfrentamento, questionamento e apropriação do mundo, a relação com o saber permite outras aproximações epistemológicas e metodológicas (CHARLOT, 2000a). Por exemplo, 
ela apontou convergências entre Freire (1996), Charlot (2000a) e Kunz (2006) como um mo(vi)mento de pesquisa. Considera importante formular melhores perguntas, e o desafio está em desvendar provisoriamente as respostas possíveis. Ela sabe que não pode pesquisar e saber sozinha. Por isso, Luciana desafiou os membros do GEPEFERS - como Cyntia e Emmanuelle - a responder, em forma de narrativa, alguns questionamentos: Estudar e pesquisar a educação física escolar e a relação com o saber faz sentido? O que me interessa no momento a respeito da educação física escolar e a relação com o saber? Em que o grupo, de fato, tem contribuído com a pesquisa que desenvolvo atualmente? $\mathrm{O}$ que proponho ao grupo para saber mais? $\mathrm{O}$ que compartilho quando aprendo com o grupo? A temática central do grupo pode contribuir com o projeto ou a pesquisa que realizo no momento? Tenho feito aproximações epistemológicas dos elementos da relação com o saber com outras teorias e/ou autores(as)?

Essas perguntas revelaram que, ao buscar reconhecer-se como alguém que estuda e pesquisa a teoria da relação com o saber, há também o intuito de conhecer o desejo do(a) outro(a). Charlot (2000a) expressou preocupação com o dinamismo de elementos, conceitos e aproximações epistemológicas, sem perder a criticidade e o compromisso com o processo de humanização. Para Luciana, esse processo requer reconhecer que há saberes, na estrutura racista e sexista de algumas universidades brasileiras, que precisam ser confrontados. O GEPEFERS é um espaço em que Luciana deseja potencializar as expressões humanas de saber e querer, enquanto se reconhece o mundo que precisa ser enfrentado, transformado, vivido e esperançado (FREIRE, 1996). Ela denuncia que é um mundo um tanto inclinado a manter na invisibilidade uma parte majoritária da história e dos saberes dos seres humanos como mulheres, negros(as), homossexuais e pobres - que tiveram suas condições de vida desqualificadas em processos contínuos (VENÂNCIO; NOBREGA, 2020).

AS RELAÇÕES IDENTITÁRIA, SOCIAL E EPISTÊMICA COM OS SABERES: TENSÕES E APROXIMAÇÕES NOS PERCURSOS DAS EXPERIÊNCIAS NARRADAS

O contexto da pandemia nos colocou diante de uma oportunidade singular de aprender por meio da reciprocidade com outros seres humanos em relações inéditas. Ao nos indagarmos a respeito da relação com um mundo de saberes, colocamo-nos em uma condição de aprender o que pode não se repetir (CHARLOT, 200oa). Como possíveis tensões, identificamos alguns marcos identitários e teóricos distintos em nossas narrativas, mesmo compartilhando o referencial de Charlot sobre a 
As relações com os saberes no processo de orientação acadêmica de...

relação com o saber. A professora-pesquisadora Cyntia é parda e bissexual. Para ela, a complexidade do estudo da relação com o saber implica em uma mobilização na educação física como precursora de uma transformação dos mecanismos mantenedores do poder (APPLE, 2006; FREIRE, 1996). Por sua vez, essa transformação afeta a atividade intelectual do(a) aluno(a) (CHARLOT, 2013a) e a radicalidade do pensamento sobre as diferenças (McLAREN, 1997).

Já para a professora-pesquisadora Emmanuelle, mulher negra e homossexual, a aproximação da relação com o saber por meio dos estudos de gênero (hooks, 2017, 2020; MARRERO, 2008) e de interseccionalidade fundamentam o seu processo de empoderamento como professora-pesquisadora. Essa visão da educação como política tem respaldo em Charlot (2013b) e Freire (1996), mas, como processo de resistência ideológica, ancora-se em Chaui (2016) e, transgressoramente, em hooks (2017). Emmanuelle assume a influência de múltiplas referências e identifica que há um processo de auto(re) construção ao aprender (CHARLOT, 200oa; SO; BETTI, 2018), permeado pela complexidade autoformativa (VENÂNCIO et al., 2016) e por convergências teórico-metodológicas (SANCHES NETO, 2003; SANCHES NETO; BETTI, 2008).

A professora-pesquisadora Luciana é negra e heterossexual. Considera que as relações com os saberes emergem de vivências, experiências, pensamentos e argumentos a partir da educação física. Essas relações, por sua vez, podem ser mobilizadas e ressignificadas na temporalidade da sua própria curiosidade, sensibilidade, criticidade e intuição. Por isso, Luciana entende que a relação com o saber pode ser vista como uma teoria socioantropológica de enfrentamento, questionamento, apropriação do mundo e inacabamento humano (CHARLOT, 1979, 2000a, 2013b). Para ela, essa perspectiva permite novas aproximações epistemológicas e metodológicas (FREIRE, 1996; KUNZ, 2006) nas investigações em educação física escolar (VENÂNCIO, 2005, 2014) e desafios que caracterizam a sua existência ancestral (VENÂNCIO, 2020), revelada com mais potência no atual contexto da pandemia (VENÂNCIO et al., 2021).

Ambas as orientandas são exemplos da concretude do pulsar humano em desvelamento existencial de saberes, mesmo que às vezes duvidem de suas potências. As atividades que realizam e os propósitos que defendem na perspectiva da justiça social são revelados nas insurgências e nas transgressões com que fazem suas práticas linguageiras enquanto se movimentam para ler o mundo e o inacabamento humano. Os elementos que compõem a teoria da relação com o saber emergem nas narrativas, explicitam os caminhos que ambas têm percorrido e revelam a noção do esperançar defendido por Paulo Freire. "Seria uma contradição se, inacabado e consciente do inacabamento, 
primeiro, o ser humano não se achasse predisposto a participar de um movimento constante de busca e, segundo, se buscasse sem esperança" (FREIRE, 1996, p. 80).

A esperança como metáfora de aproximação ao sentido das relações com os saberes é o móbil que as impulsiona, como recurso e necessidade ontológica dos seus atos políticos expressos nas narrativas. As narrativas são possibilidades de mantermos a esperança, ao situar o entendimento de si, enquanto lemos o mundo, porque permitem a convergência de modos de pensar, falar e escrever informal, social e academicamente. Como pondera Venâncio (2014), Charlot e Freire concordam que é preciso reconhecer a importância de aprender e estabelecer relações com o mundo enquanto se percebe o inacabamento do ser. As narrativas das duas orientandas são práticas linguageiras que sofrem pressão e opressão, revelando que ambas se orientam com quem também está aprendendo a ser.

A prática linguageira é uma prática social. Primeiro, porque o sujeito mesmo é social: ele aprendeu a falar por meio de sua socialização familiar e seu relacionamento com outros jovens; o que e como ele fala diz respeito ao que ele é de um ponto de vista social. Segundo, a prática linguageira é social porque se fala em situações sociais, sendo articulada com outras práticas (trabalhar, brigar, namorar...). Pelo fato de ser social, ela é estruturada por normas que variam conforme os meios sociais. (CHARLOT, 200ob, p. 8).

Olhando essa perspectiva de situar a prática linguageira como práxis discursiva, escrita da fala pensada e recurso da memória, as narrativas tornam-se modos insurgentes e transgressores de abalar as estruturas da omissão de certas práticas linguageiras que socialmente revelam as tentativas de ocultar vozes, escutas e histórias de vidas. Assim como o GEPEFERS, os grupos acadêmicos são espaços-tempos para enunciados de práticas sociais e de saberes, que precisam ser ocupados por seres humanos capazes de gerar dúvidas constantemente - enquanto falam e são ouvidos. E, assim, constituem-se em lócus de confronto das hierarquias de saberes. Ao narrar suas próprias relações com os saberes enquanto desvelam as relações de outros seres humanos com os saberes, Cyntia e Emmanuelle apontam indícios de como Luciana pode valorizar as intersubjetividades no processo de orientação. Mesmo atreladas a um programa de pós-graduação e a um grupo de pesquisa, podemos constituir espaços-tempos humanos de convergências, insurgências e transgressões de saberes para promover a justiça social e combater o racismo, o sexismo, a homofobia, a misoginia e as mais variadas formas de opressão engendradas pela colonização do pensamento. 
As relações com os saberes no processo de orientação acadêmica de...

\section{CONSIDERAÇÕES}

Consideramos que nós, como professoras-pesquisadoras, engajamo-nos efetivamente com pessoas, lugares, atividades, objetos e com os(as) outros(as), conosco mesmas e com o tempo. Entendemos que os meandros do processo de orientação acadêmica apontam que os objetos de pesquisa precisam emergir a partir do que cada professora-pesquisadora entende por educação física escolar progressista, transformadora, crítica e dialógica. Esse processo pode levar a convergências de sentidos sobre ensinar-aprender-estudar-pesquisar com e na educação física, porque as investigações da teoria da relação com o saber têm como prerrogativa a valorização da intersubjetividade - baseada na diversidade, na criticidade, na equidade e na justiça social - e assumem a forma de um quadro teórico complexo, e necessariamente plural, de relações com os saberes. As dimensões identitária, social e epistêmica - convergentes nas figuras do aprender (CHARLOT, 2000a) - assinalam que cada sujeito, no percurso da sua trajetória, confere a pessoas, lugares e tempo as mais variadas formas de saber com o mundo.

As nossas narrativas entrelaçaram-se com os recursos que cada uma de nós tem mobilizado para aprender. Assim, não há somente uma imposição da obrigação de aprender, na lógica antropológica que subsidia a relação com o saber proposta por Charlot (2000a). Além disso, cada ser humano - ao se reconhecer como sujeito em relação ao mundo - toma posse de saberes que ampliam a sua própria consciência de si, em relação aos(às) outros(as) e em relação aos saberes. Concluímos que o desafio de narrar aspectos da nossa própria experiência (auto)formativa, circunscrita ao processo de orientação acadêmica, fomentou nossa interlocução como professoras-pesquisadoras e permitiu olhares diferentes para as aproximações com a teoria da relação com o saber, que têm sido realizadas no campo investigativo da educação física escolar. Esse desafio também possibilitou compreendermos melhor como as nossas próprias relações com os saberes se constituíram - identitária, social e epistemologicamente - de modo não hierárquico, a despeito da tensão inerente ao vínculo institucional como orientadora e orientandas.

\section{REFERÊNCIAS}

ABREU, S. M. B. de; NÓBREGA-THERRIEN, S. M. Aprendizagens didáticas pela alteridade: experiência autoformadora na supervisão no PIBID educação física do IFCE. Cenas Educacionais, 
Caetité-BA, v. 4, n. e10655, p. 1-15, 2021. Disponível em: https://www.revistas.uneb.br/index.php/ cenaseducacionais/article/view/10655. Acesso em: 7 fev. 2021.

APPLE, M. Ideologia e currículo. 3. ed. Porto Alegre: Artmed, 2006.

ARENDT, H. A condição humana. 10. ed. Rio de Janeiro: Forense, 2007.

CHARLOT, B. A mistificação pedagógica: realidades sociais e processos ideológicos na teoria da educação. Rio de Janeiro: Zahar, 1979.

CHARLOT, B. Da relação com o saber: elementos para uma teoria. Porto Alegre: Artmed, 2000 .

CHARLOT, B. Práticas linguageiras e fracasso escolar. Estilos da Clínica, São Paulo, v. 5, n. 9, p. 124$133,2000 b$.

CHARLOT, B. Relação com o saber, formação de professores e globalização: questões para a educação hoje. Porto Alegre: Artmed, 2005.

CHARLOT, B. A pesquisa educacional entre conhecimentos, políticas e práticas: especificidades e desafios de uma área de saber. Revista Brasileira de Educação, Rio de Janeiro, v. 11, n. 31, p. 7-18, jan./abr. 2006.

CHARLOT, B. Da relação com o saber às práticas educativas. Porto Alegre: Cortez, 2013 a.

CHARLOT, B. A mistificação pedagógica: realidades sociais e processos ideológicos na teoria da educação. São Paulo: Cortez, 2013b.

CHARLOT, B. A questão antropológica na Educação quando o tempo da barbárie está de volta. Educar em Revista, Curitiba, v. 35, n. 73, p. 161-180, 2019. Disponível em: http://dx.doi. org/10.1590/o104-4060.62350. Acesso em: 5 fev. 2021.

CHARLOT, B. Educação ou barbárie? Uma escolha para a sociedade contemporânea. São Paulo: Cortez, 2020.

CHAUI, M. Ideologia e educação. Educação e Pesquisa, São Paulo, v. 42, n. 1, p. 245-257, jan./mar. 2016.

COLLINS, P. H. O que é um nome? Mulherismo, feminismo negro e além disso. Cadernos Pagú, Campinas-SP, n. 51, e175118, 2017. DOI: https://doi.org/10.1590/18094449201700510018.

ELLIOTT, J. Editorial review: Lesson study as curriculum analysis (Kyouzai Kenkyuu) in action and the role of "the teacher as a researcher". International Journal for Lesson and Learning Studies, Bingley, v. 6, n. 1, p. 2-9, 2017. Disponível em: https://doi.org/10.1108/IJLLS-11-2016-0045. Acesso em: 5 fev. 2021.

FLOR, B. J. M. S. et al. Planejamento participativo como instrumento político e pedagógico em aulas de educação física no programa de residência pedagógica. Revista Brasileira de Educação Física Escolar, Curitiba, v. 4, n. 2, p. 123-137, 2020. Disponível em: https://editoracrv.com.br/ produtos/detalhes/35437-ano-vi-volumes-ii-novembro-2020-br-revista-brasileira-de-educacaofisica-escolar-rebescolar. Acesso em 06 set. 2021.

FREIRE, P. Pedagogia da autonomia: saberes necessários à prática educativa. São Paulo: Paz e Terra, 1996.

GOMES, N. L. O movimento negro educador: saberes construídos nas lutas por emancipação. Petrópolis-RJ: Vozes, 2017.

HOOKS, B. Ensinando a transgredir: a educação como prática da liberdade. São Paulo: Editora WMF, 2017.

HOOKS, B. Educação democrática. In: CÁSSIO, F. (Org.) Educação contra a barbárie: por escolas democráticas e pela liberdade de ensinar. São Paulo: Boitempo, 2019. p. 200. 
As relações com os saberes no processo de orientação acadêmica de...

HOOKS, B. E eu não sou uma mulher?: mulheres negras e feminismo. Rio de Janeiro: Rosa dos Tempos, 2020.

JOSSO, M. C. Histórias de vida e formação: suas funcionalidades em pesquisa, formação e práticas sociais. Revista Brasileira de Pesquisa (Auto)biográfica, Cabula - BA, v. 5, n. 13, p. 40-54, 2020.

KUNZ, E. Educação física crítico-emancipatória. Ijuí-RS: Unijuí, 2006.

LARROSA BONDÍA, J. Tremores: escritos sobre experiência. Belo Horizonte: Autêntica, 2014.

LIMA, C. E. S. et al. Breaking cultural "taboos" about the body and gender: Brazilian students' emancipation from a thematic perspective of school physical education. Frontiers in Education, Lausanne, v. 5, n. 155, p. 1-8, 2020. Disponível em: https://doi.org/10.3389/feduc.2020.00155. Acesso em: 5 fev. 2021.

LUTTRELL, W. (Org.). Qualitative educational research: readings in reflexive methodology and transformative practice. Londres: Routledge, 2010.

MARRERO, A. La escuela transformadora. Evidencias sobre las relaciones entre educación y género. Uma propuesta teórica de interpretación. Papers, Barcelona, v. 90, p. 191-211, 2008. Disponível em: http://papers.uab.cat/article/view/v9o-marrero. Acesso em: o5 jan. 2021.

McLAREN, P. A vida nas escolas: uma introdução à pedagogia crítica nos fundamentos da educação. Porto Alegre: Artes Médicas, 1997.

NOBRE, A. F. et al. Reflexões sobre as apropriações dos elementos da teoria da relação com o saber na educação física escolar. Revista Estudos de Cultura, São Cristóvão - SE, v. 5, n. 14, p. 103-116, set. 2019. Disponível em: https://seer.ufs.br/index.php/revec/issue/view/1010. Acesso em: 05 jan. 2021.

SANCHES NETO, L. Educação física escolar: uma proposta para o componente curricular da $5^{\text {a }}$ à $8^{\text {a }}$ série do ensino fundamental. Dissertação (Mestrado em Pedagogia da Motricidade Humana) Universidade Estadual Paulista, Instituto de Biociências, Rio Claro - SP, 2003.

SANCHES NETO, L.; BETTI, M. Convergência e integração: uma proposta para a educação física de $5^{a}$ à $8^{a}$ série do ensino fundamental. Revista Brasileira de Educação Física e Esporte, São Paulo, v. 22, n. 1, p. 5-23, 2008. Disponível em: http://www.revistas.usp.br/rbefe/article/view/16678. Acesso em: 23 maio 2020.

SANCHES NETO, L.; VENÂNCIO, L. A luta por visibilidade des afrolatines como desafio curricular à educação física antirracista. In: FILGUEIRAS, I. P.; MALDONADO, D. T. Currículo e prática pedagógica de educação física escolar na América Latina. Curitiba: CRV, 2020. p. 29-42.

SANDÍN-ESTEBAN, M. P. Pesquisa qualitativa em educação: fundamentos e tradições. Porto Alegre: AMGH, 2010.

SILVA, A. J. F. et al. Desafios da educação física escolar em tempos de pandemia: notas sobre estratégias e dilemas de professores(as) em tempo de combate à covid-19 (SARS-CoV-2). Cenas Educacionais, Caetité-BA, v. 4, n. e10618, p. 1-27, 2021. Disponível em: https://www.revistas.uneb. br/index.php/cenaseducacionais/announcement/view/10618/780o. Acesso em: 6 set. 2021.

SILVA, P. B. G.; BERNARDES, N. M. G. Roda de conversas: excelência acadêmica é a diversidade. Educação, Porto Alegre, v. 61, n. 1, p. 53-92, 2007. Disponível em: https://revistaseletronicas.pucrs. $\mathrm{br} /$ index.php/faced/article/view/540/376. Acesso em: 06 jan. 2021.

SO, M. R.; BETTI, M. Sentido, mobilização e aprendizagem: as relações dos alunos com os saberes das lutas nas aulas de educação física. Movimento, Porto Alegre, v. 24, n. 2, p. 555-568, abr./jun. 2018. 
VENÂNCIO, L. Projeto-político-pedagógico e a educação física escolar no processo de construção coletiva. Dissertação (Mestrado em Ciências da Motricidade) - Universidade Estadual Paulista, Rio Claro - SP, 2005.

VENÂNCIO, L. O que nós sabemos? Da relação com o saber na e com a educação física em um processo educacional-escolar. 2014. 294f. Tese (Doutorado) - Programa de Pós-Graduação em Educação, Universidade Estadual Paulista, Presidente Prudente/SP.

VENÂNCIO, L. A relação com o saber e o tempo pedagogicamente necessário: narrativas de experiência com a educação física escolar. Revista Estudos de Cultura, São Cristóvão - SE, v. 5, n. 14, p. 89-102, set. 2019. Disponível em: https://seer.ufs.br/index.php/revec/issue/view/1010. Acesso em: 05 jan. 2021.

VENÂNCIO, L. Abre a roda que eu quero entrar: da ciranda do racismo ao enfrentamento do mundo. In: VENÂNCIO, L.; NOBREGA, C. C. S. Mulheres negras professoras de educação física. Curitiba, CRV, 2020. p. 185-206.

VENÂNCIO, L. et al. Modos de abordar a aprendizagem na educação física escolar: sujeitos interlocutores na relação com o saber. Revista Brasileira de Educação Física Escolar, Curitiba, n. 2, v. 3, p. 32-53, mar. 2016.

VENÂNCIO, L. et al. Temas e desafios (auto)formativos para professores de educação física à luz da didática e da justiça social. Cenas Educacionais, Caetité-BA, v. 4, n. e10778, p. 1-40, 2021. Disponível em: https://revistas.uneb.br/index.php/cenaseducacionais/article/view/10778. Acesso em: 06 set. 2021.

VENÂNCIO, L.; NOBREGA, C. C. S. Mulheres negras professoras de educação física. Curitiba: CRV, 2020. VENÂNCIO, L.; SANCHES NETO, L. Narrativas e assunções como catalisadores dos percursos metodológicos das relações com o saber na educação física. International Journal Education and Teaching PDVL, Recife, v. 1, n. 2, p. 82-103, 2018. Disponível em: https://ijet-pdvl.com/index.php/ $\mathrm{pdvl} /$ article/view/46. Acesso em: 8 jan. 2021.

VENÂNCIO, L.; SANCHES NETO, L. A relação com o saber em uma perspectiva (auto)biográfica na educação física escolar. Revista Brasileira de Pesquisa (Auto)Biográfica, Salvador, v. 4, n. 11, p. 729-750, maio/ago. 2019. Disponível em: https://www.revistas.uneb.br/index.php/rbpab/ article/view/4366. Acesso em: 06 fev. 2021.

\section{SOBRE AS AUTORAS}

Luciana Venâncio é licenciada em Educação Física pela Universidade Estadual Paulista/Unesp - Rio Claro, Especialista em Educação Física Escolar/FEF Unicamp, Mestre em Educação Física Escolar pela Unesp - Rio Claro, Doutora em Educação pela Unesp - Presidente Prudente. Foi bolsista de Doutorado FAPESP (2010-2014). Atualmente é professora Adjunta na Universidade Federal do Ceará, no Instituto de Educação Física e Esportes (IEFEs) e docente permanente do Programa de Pós-Graduação em Educação Física da Universidade Federal do Rio 
Grande do Norte, Natal. Coordenadora do Programa de Residência Pedagógica do Projeto Subprojeto Educação Física (2018-2020). Realizou Pós-Doutorado em Educação na Universidade Federal de Sergipe (UFS) sob a supervisão do Prof. Dr. Bernard Charlot. Tem experiência docente no Ensino Superior e na Pós-graduação (Lato Sensu) em Educação Física. Professora efetiva de Educação Física na Rede de Educação Básica do Município de São Paulo (1998-2016). Estuda e pesquisa temas referentes a educação física escolar, relação com o saber, projeto político-pedagógico, planejamento participativo, sistematização de conteúdos, pesquisa-ação, processo de ensino e aprendizagem com ênfase nos saberes discentes, didática e estágio supervisionado e educação antirracista. Membro do International Study Association on Teachers and Teaching (ISATT). Membro da Rede de Pesquisa sobre a Relação com o Saber (REPERES). É também membro do grupo autônomo de professores-pesquisadores em Educação Física Escolar. Coordenadora do Grupo de Estudos e Pesquisas em Educação Física Escolar e Relações com os saberes (GEPEFERS).

ORCID ID: https://orcid.org/oooo-0oo3-2903-7627.

E-mail: luciana_venancio@yahoo.com.br.

Cyntia Emanuelle Souza Lima é mestranda no Programa de Pós-Graduação em Educação Física da Universidade Federal do Rio Grande do Norte. Licenciada em Educação Física pela Universidade Federal do Ceará. Membro do Grupo de Estudos e Pesquisas em Educação Física Escolar e Relações com os saberes (GEPEFERS). ORCID ID: https://orcid.org/oooo-0003-3247-0907.

E-mail: cyntiaeslima@gmail.com.

Emmanuelle Cynthia da Silva Ferreira é mestranda no Programa de PósGraduação em Educação Física da Universidade Federal do Rio Grande do Norte. Licenciada em Educação Física pela Universidade Federal do Ceará. Membro do Grupo de Estudos e Pesquisas em Educação Física Escolar e Relações com os saberes (GEPEFERS).

ORCID ID: https://orcid.org/oooo-0oo2-7100-5138.

E-mail: cyntiaeslima@gmail.com.

Recebido em 16 de fevereiro de 2021 e aprovado em 14 de julho de 2021. 